\title{
Instrumentation Failure after Partial Corpectomy with Instrumentation of a Metastatic Spine
}

\author{
Sung Bae Park, M.D., Ph.D., Ki Jeong Kim, M.D., Ph.D., ${ }^{2}$ Sanghyun Han, M.D., ${ }^{2}$ Sohee Oh, Ph.D., ${ }^{3}$ Chi Heon Kim, M.D., Ph.D., ${ }^{4,5}$ \\ Chun Kee Chung, M.D., Ph.D. ${ }^{4-7}$ \\ Department of Neurosurgery, Seoul National University Boramae Medical Center, Seoul, Korea \\ Department of Neurosurgery, ${ }^{2}$ Spine Center, Seoul National University Bundang Hospital, Seoul National University College of Medicine, \\ Seongnam, Korea \\ Department of Biostatistics, ${ }^{3}$ Seoul National University Boramae Medical Center, Seoul, Korea \\ Department of Neurosurgery, ${ }^{4}$ Seoul National University College of Medicine, Seoul, Korea \\ Clinical Research Institute, ${ }^{5}$ Seoul National University Hospital, Seoul, Korea \\ Neuroscience Research Institute, 6 Seoul National University Medical Research Center, Seoul, Korea \\ Department of Brain and Cognitive Sciences, ${ }^{7}$ Seoul National University College of Natural Sciences, Seoul, Korea
}

Objective : To identify the perioperative factors associated with instrument failure in patients undergoing a partial corpectomy with instrumentation (PCl) for spinal metastasis.

Methods : We assessed the one hundred twenty-four patients with who underwent PCI for a metastatic spine from 1987 to 2011. Outcome measure was the risk factor related to implantation failure. The preoperative factors analyzed were age, sex, ambulation, American Spinal Injury Association grade, bone mineral density, use of steroid, primary tumor site, number of vertebrae with metastasis, extra-bone metastasis, preoperative adjuvant chemotherapy, and preoperative spinal radiotherapy. The intraoperative factors were the number of fixed vertebrae, fixation in osteolytic vertebrae, bone grafting, and type of surgical approach. The postoperative factors included postoperative adjuvant chemotherapy and spinal radiotherapy. This study was supported by the National Research Foundation grant funded by government. There were no study-specific biases related to conflicts of interest.

Results : There were 15 instrumentation failures (15/124, 12.1\%). Preoperative ambulatory status and primary tumor site were not significantly related to the development of implant failure. There were no significant associations between insertion of a bone graft into the partial corpectomy site and instrumentation failure. The preoperative and operative factors analyzed were not significantly related to instrumentation failure. In univariable and multivariable analyses, postoperative spinal radiotherapy was the only significant variable related to instrumentation failure ( $p=0.049$ and 0.050 , respectively).

Conclusion : When performing $\mathrm{PCl}$ in patients with spinal metastasis followed by postoperative spinal radiotherapy, the surgeon may consider the possibility of instrumentation failure and find other strategies for augmentation than the use of a bone graft for fusion.

Key Words : Spine · Metastasis · Decompression · Radiotherapy.

\footnotetext{
- Received : May 15, 2017 •Revised : August 13, 2017 •Accepted : September 6, 2017

-Address for reprints : Chun Kee Chung, M.D., Ph.D.

Department of Neurosurgery, Seoul National University Hospital, 101 Daehak-ro, Jongno-gu, Seoul 03080, Korea

Tel : +82-2-2072-2352, Fax : +82-2-744-8459, E-mail : chungc@snu.ac.kr
}

This is an Open Access article distributed under the terms of the Creative Commons Attribution Non-Commercial License (http://creativecommons.org/licenses/by-nc/4.0) which permits unrestricted non-commercial use, distribution, and reproduction in any medium, provided the original work is properly cited. 


\section{INTRODUCTION}

Cancer is the leading cause of death, and bone metastasis occurs in $15-70 \%$ of patients with carcinoma of the lung, colon, or stomach, or in those with advanced breast or prostate cancer ${ }^{4,13,22}$. Up to $70 \%$ of patients with cancer harbor spinal metastases ${ }^{9,12)}$, which can cause pathological fractures, spinal cord compression, other nerve compression syndromes, and life-threatening hypercalcemia ${ }^{22,26)}$. The symptoms of spinal metastasis are back pain, weakness, sensory deficits, and autonomic dysfunction ${ }^{17)}$. Age, sex, comorbidities, and the primary tumor site affect the survival rate of patients with a metastatic spine tumor ${ }^{23}$. Surgery, radiotherapy, chemotherapy, and various combinations of these three modalities are used in the management of patients with spinal metastases ${ }^{2,14}$. Although decompression surgery alone is a good treatment for patients with spinal cord compression, preoperative or intraoperative spinal instability associated with a metastatic spine tumor might necessitate spinal stabilization using instrumentation $^{16,26)}$. In patients with spinal metastases, the rate of spinal bone fusion is low, with a $16 \%$ rate of pseudarthrosis 1 year postoperatively because of adjuvant therapy, use of steroids, and malnutrition ${ }^{6,21)}$. Therefore, in patients with a short-term life expectancy of less than 6 months, the use of methyl methacrylate is recommended over bone grafting for anterior support of the spine after corpectomy ${ }^{20,26)}$.

The ability to identify patients with spinal metastasis who might not need bone grafting in addition to instrumented stabilization might improve the surgical outcome by decreasing the surgery time and complications associated with bone grafting. To our knowledge, no study has described the instrumentation failure rate and perioperative factors related to instrumentation failure, including the need for bone grafting in the corpectomy bed, in patients who undergo palliative metastatic spine surgery. Therefore, this study aimed to identify the instrumentation failure rate and the perioperative factors, including bone grafting, associated with instrumentation failure in patients who have undergone partial corpectomy of a metastatic spine.

\section{MATERIALS AND METHODS}

\section{Patients}

The clinical records of all patients with a metastatic spine tumor who underwent surgical treatment with instrumented stabilization from 1987 to 2011 in two hospitals were reviewed retrospectively. We enrolled those patients who underwent partial corpectomy with instrumentation (PCI) for spinal metastases and excluded those patients who underwent only vertebroplasty, biopsy, decompressive laminectomy alone, decompressive laminectomy with transpedicular screw fixation, total spondylectomy, or root blockage. We also excluded those patients whose medical records and radiology images were not available for review. Instrumentation failure was defined as transpedicular screw loosening, fracture of the rod placed between the screws, or displacement of the struts in the cage, cement, or bone during the follow-up period. Four surgeons operated on patients with a metastatic spine tumor in two affiliated hospitals of a single institute.

For patients with multiple levels of spine involvement, all surgeons performed decompressive surgery, including partial corpectomy, at the levels of cord compression. The fixation level using instrumentation depended on the surgical approach. When the dorsal approach alone was used, we performed upper and lower two-level transpedicular screw fixation. When the ventral approach alone was used, the graft was inserted at the corpectomy level followed by upper and lower one-level fixation. When the combined anterior and posterior approach was used, we performed upper and lower one-level fixation. The strategy for the use of bone grafting was at the surgeons' discretion, although none of the surgeons used bone grafting into the corpectomy site in patients with a life expectancy of less than 6 months.

\section{Factors associated with instrumentation failure}

Various factors were selected for evaluation of their association with instrumentation failure after metastatic spine surgery. The preoperative factors considered were age, sex, Tomita score, American Spinal Injury Association grade, preoperative ambulatory status, bone mineral density, use of steroid, primary tumor site, number of vertebrae with metastasis, the presence of extra-bone metastasis, preoperative adjuvant therapy, and preoperative spinal radiotherapy ${ }^{3,5,25)}$. Because the primary tumor site was variable, the primary tumor site was 
classified as the kidney, liver, lung, or other site according to the frequency of the affected organ with the primary tumor. The intraoperative factors were the number of vertebrae fixed, level of spine operated (cervical, thoracic, and lumbar), fixation in osteolytic vertebrae, use of bone grafting, and type of approach (ventral alone, dorsal alone, combination of ventral and dorsal). The postoperative factors were the use of postoperative adjuvant therapy and spinal radiotherapy.

\section{Statistical analysis}

Statistical analyses were performed using R software version 3.3.1. To analyze the association between instrumentation failure and bone fusion, and to identify any significant factors, a two-sample Student's t test was used to compare continuous variables, and Pearson's chi-squared or Fisher's exact test was used to compare categorical variables. To account for the small number of events, logistic regression with Firth's penalized likelihood ${ }^{7)}$ was used for univariable and multivariable analyses of the relationships between instrumentation failure and perioperative factors. Two-sided $p$ values of $<0.05$ were assumed to be significant.

\section{RESULTS}

\section{Patient data}

One hundred twenty-four patients who underwent PCI and had available medical data were enrolled finally (72 males and 52 females; mean age, $57.4 \pm 11.68$ years; range, $20-81$ ). The primary tumor site was variable between patients. The most common primary tumor site was the lung $(n=32)$, followed by the liver $(\mathrm{n}=22)$ and kidney $(\mathrm{n}=9)$. Other sites $(\mathrm{n}=61)$ were colon or rectum, thyroid, breast, prostate, stomach, esophagus, oral cavity, pancreas, gall bladder, ureter, skin, and blood related. Seventy-five percent (93/124) of patients were ambulatory before PCI.

The most common vertebra level of the metastatic spine tumor was the thoracic level $(n=54,43.5 \%)$, followed by the cervical and lumbar vertebrae $(n=16,37.1 \%$ and $n=24,19.4 \%$, respectively). Therefore, thoracic vertebrae were the most commonly instrumented $(\mathrm{n}=54,43.5 \%)$, followed by the cervical $(n=46,37.1 \%)$ and lumbar $(n=24,19.4 \%)$ vertebrae. The mean number of metastatic spine and fixed vertebrae were 3.0 \pm 4.4 and $3.0 \pm 1.2$, respectively. Sixty-two patients underwent bone grafting into the corpectomy site with a cage or bone strut. The mean and median survival time after spine surgery was $452 \pm 752.2$ days and 545 days (12-6103 days).

Fifteen patients experienced instrumentation failure (15/124, $12.1 \%)$. The lung was the most common primary tumor site in the instrumentation failure group. The lumbar spine was the most frequent site of metastatic vertebrae associated with instrumentation failure : four of 24 (16.6\%) patients with lumbar spinal metastases experienced instrumentation failure; the respective values were 6/54 (11.1\%) and 5/46 (10.8\%) for patients with thoracic metastasis or cervical spinal metastases, respectively. Although the mean and median day of occurrence of instrumentation failure after surgery was $535 \pm 1258.0$ days and 168 days (2-4948 days), 80\% (12/15) of those patients who experienced instrumentation failure did so within 1 year after surgery. The mean and median survival time after surgery was $941 \pm 1486.8$ and 545 days (84-6103 days). However, none of the 12 patients who experienced instrumentation failure within 1 year after surgery survived for more than 3 years after surgery (Table 1). Screw loosening was the most common type of instrumentation failure (Fig. 1).

\section{Factors related to instrumentation failure}

In the comparison of the risk factors between the instrumentation failure and nonfailure groups, postoperative spinal radiotherapy was the only significant factor related to instrument failure ( $p=0.049$ ). Preoperative factors including ambulatory status, primary tumor site, bone mineral density, use of steroid, and Tomita score were not significantly related to instrumentation failure. Intraoperative factors such as the surgical approach, fixation in osteolytic vertebrae, bone grafting, and fixation level were not significantly related to instrumentation failure (Table 2).

In the logistic regression analysis of the risk factors related to instrumentation failure, the use of postoperative spinal radiotherapy was significant in the univariable analysis $(p=0.049)$. Ambulatory status was the other factor with a $p$ value $<0.20$ in the univariable analysis. We performed multivariable analysis that included postoperative spinal radiotherapy and ambulatory status. The use of postoperative spinal radiotherapy was the only significant factor in multivariable analysis (odds ratio $[\mathrm{OR}]=3.535,95 \%$ confidence interval $[C I]=1.001-18.701, p=0.050$ ). Bone mineral density, use of steroid, grafting, number of fixed vertebrae, fixation in osteolytic 
Table 1. Summary of the patients with instrumentation failure

\begin{tabular}{|c|c|c|c|c|c|c|c|}
\hline Case No. & Sex & Age (years) & Primary tumor & $\begin{array}{c}\text { Metastatic } \\
\text { vertebrae }\end{array}$ & $\begin{array}{c}\text { Instrumentation } \\
\text { failure (bone grafting; } \\
\text { yes or no) }\end{array}$ & $\begin{array}{l}\text { Instrumentation } \\
\text { failure time after } \\
\text { surgery (days) }\end{array}$ & $\begin{array}{l}\text { Survival time } \\
\text { after surgery } \\
\text { (days) }\end{array}$ \\
\hline 1 & M & 65 & Liver & C & SD \& SL (yes) & 2 & 84 \\
\hline 2 & $\mathrm{~F}$ & 49 & Lung & $\mathrm{T}$ & SD (yes) & 3 & 1313 \\
\hline 3 & $\mathrm{~F}$ & 46 & Breast & $\mathrm{T}$ & $\mathrm{SL}$ (no) & 12 & 884 \\
\hline 4 & $\mathrm{~F}$ & 44 & Gall bladder & C & SL (yes) & 45 & 140 \\
\hline 5 & $\mathrm{~F}$ & 51 & Thyroid & C & $\mathrm{SD}(\mathrm{no})$ & 48 & 243 \\
\hline 6 & M & 67 & Vascular & $\mathrm{T}$ & SD \& SL (no) & 75 & 225 \\
\hline 7 & M & 79 & Lung & $L$ & SL (yes) & 79 & 142 \\
\hline 8 & M & 66 & Lung & L & SL (no) & 168 & 731 \\
\hline 9 & M & 53 & Liver & C & SD \& SL (yes) & 178 & 349 \\
\hline 10 & M & 65 & Prostate & $\mathrm{T}$ & SL (yes) & 212 & 574 \\
\hline 11 & M & 69 & Esophagus & $L$ & SD \& SL (yes) & 295 & 477 \\
\hline 12 & $F$ & 73 & MUO & $\mathrm{T}$ & SL (yes) & 299 & 545 \\
\hline 13 & M & 53 & Lung & $\mathrm{T}$ & SL (yes) & 451 & 871 \\
\hline 14 & $\mathrm{~F}$ & 51 & Lung & L & $\mathrm{RF}(\mathrm{no})$ & 1212 & 1434 \\
\hline 15 & $\mathrm{~F}$ & 45 & Thyroid & C & $\mathrm{SL}$ (no) & 4948 & 6103 \\
\hline
\end{tabular}

$M$ : male, F : female, $C$ : cervical spine, SD : strut displacement, SL : screw loosening, $T$ : thoracic spine, L : lumbar spine, RF : rod fracture

vertebrae, and type of approach were not significant $(p=0.438$, $0.754,0.783,0.872,0.266$, and 0.386 , respectively) (Table 3 ). Also, in comparison between non-instrument failure group and other group with instrument failure over three months after surgery, there was no significant difference and significant factor related to instrument failure.

\section{DISCUSSION}

Among the 214 patients in this study, 15 experienced instrument failure, such as the loosening of a pedicle screw, strut displacement, or screw fracture. The mean time to instrumentation failure was 535 days, and the mean survival time was 452 days after spinal surgery. However, in 12 of the 15 patients $(80 \%)$ who experienced instrumentation failure, the failure occurred within 365 days and none of the patients survived more than three years after surgery. Multivariable analysis identified only one significant factor associated with instrumentation failure : the use of postoperative spine radiotherapy.

Animal studies have shown that radiation therapy affects spine fusion unfavorably by reducing the fusion mass and stiffness of the fusion ${ }^{3,5)}$. Although local control induced by radiation therapy, including radiosurgery, is effective, there are few human studies of spine fusion with perioperative radiation therapy. Emery et al. ${ }^{6}$ reported a 16\% fusion failure rate in patients treated with corpectomy and reconstruction with an autologous bone graft. All patients underwent radiation therapy either before or after surgery. Harel et al. ${ }^{10)}$ studied spine instrumentation failure after spine tumor resection and radiation, given as conventional fractionated radiation (XRT) or stereotactic spine radiosurgery (SRS). The instrumentation failure rates were $43 \%$ and $0 \%$, and the fusion rates were $17 \%$ and 50\% in the XRT and SRS groups, respectively. In the present study, 79 patients underwent postoperative radiotherapy but not radiosurgery of the spine, and 13 of these 70 patients (16.4\%) experienced instrumentation failure regardless of whether they had or had not received a bone graft. The rationale for radiation therapy is to achieve local control of the residual tumor after surgery ${ }^{18)}$. Radiation therapy decreases bone strength and interferes with the normal healing and fusion process $^{3,5,24)}$. Postoperative radiation therapy was the only significant factor related to instrumentation failure in our study.

Patients with a metastatic spine tumor might have limited capability for bone formation because of the effects of malnutrition and perioperative adjuvant therapies, including chemo- 


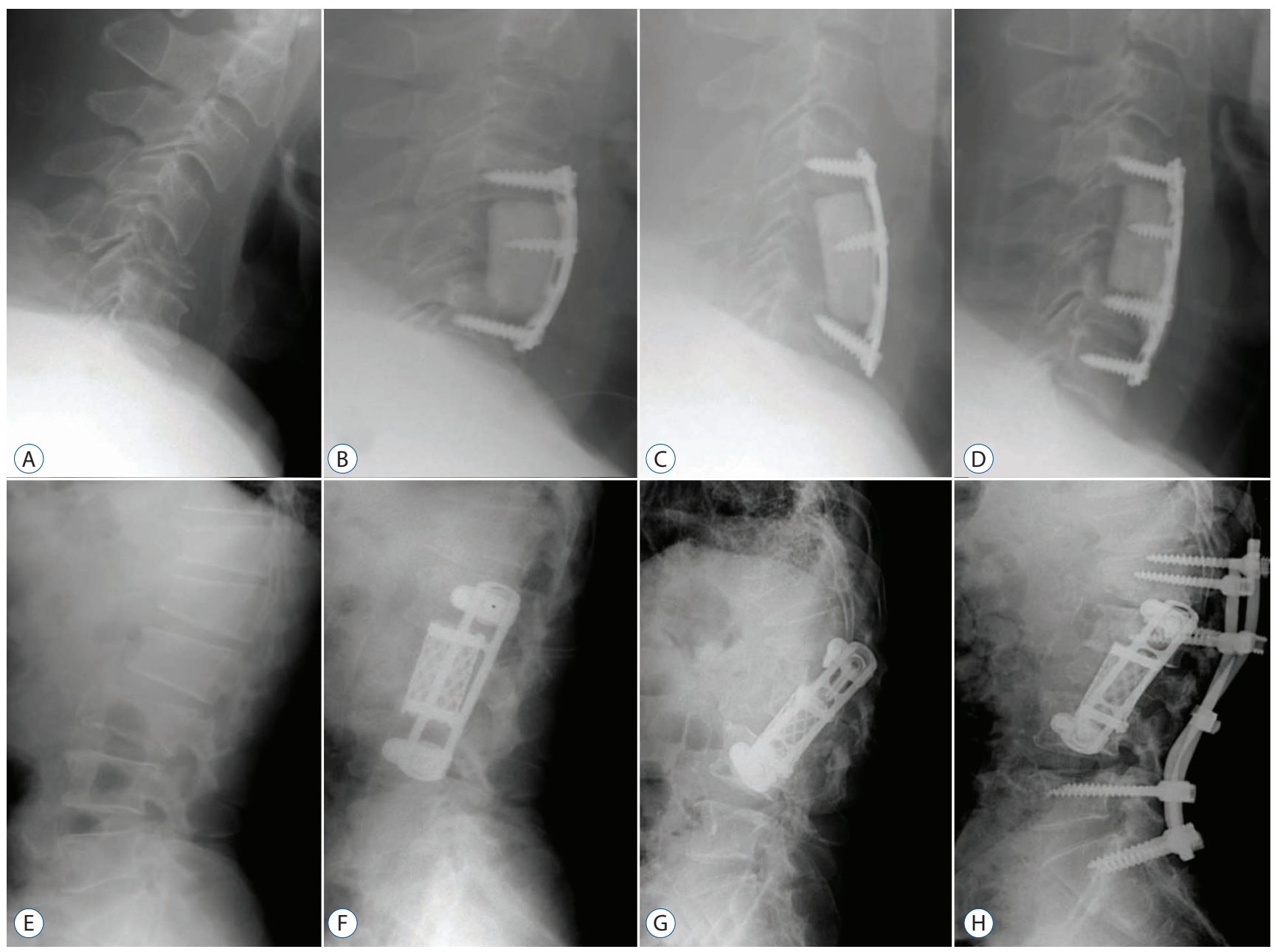

Fig. 1. Plain X-rays show examples of instrumentation failure such as ( $A$ and $D$ ) instrumentationdisplacement including a methylmethacrylate strut in a patient with hepatocellular carcinoma and metastasis in the cervical spine and $(E$ and $H)$ instrumentationdisplacement in a patient with esophageal carcinoma and metastasis in the lumbar spine. A : Preoperative plain X-ray. B : Immediate postoperative plain X-ray. C : Plain X-ray on the second day after surgery. D : Plain X-ray after revision surgery. We performed additional fixation at C7. E : Preoperative plain X-ray. F : Immediate postoperative plain X-ray. G : Plain X-ray on the 295th day after surgery. $\mathrm{H}$ : Plain X-ray after revision surgery. We performed the additional posterior fixation.

therapy, radiotherapy, and steroids ${ }^{21)}$. Surgical treatment with or without stabilization followed by radiation therapy is recommended for patients with a metastatic spine tumor and cord compression ${ }^{1,15}$. Adjuvant therapy can impair bone remodeling, which may reduce the pull-out strength and rate of bone formation. In the present study, the number of fixed vertebrae, use of bone grafting, and surgical approach were not significantly related to instrumentation failure. In addition, the fusion-augmentation technique using a bone graft seemed not to be effective. These results suggest that bone grafting might not be essential for preventing instrumentation failure in patients with less than one year of life expectancy. This result also supports the idea that a structurally sound construct with fixation augmentation is more important than bone grafting in the surgical treatment of spinal metastasis.

The aim of the surgical treatment of spinal metastasis is to relieve neural compression, spinal instability, deformity, intractable pain, and failure of radiotherapy ${ }^{8,11,19)}$. In the present study, 15 of the 124 patients (12.1\%) developed instrumentation failure, and 12 of these 15 patients (80\%) experienced instrumentation failure within 1 year postoperatively. The nine $(60 \%, 9 / 15)$ and $12(80 \%, 12 / 15)$ patients survived until postoperative 1 and 2 years, respectively. The rate of instrumentation failure was not high, and most cases occurred within 1 year after the operation. Therefore, if the life expectancy of a patient undergoing surgery for spinal metastasis is less than 
J Korean Neurosurg Soc 61 | May 2018

Table 2. Comparison of parameters in two groups

\begin{tabular}{|c|c|c|c|}
\hline Risk factor & Non-failure $(n=109)$ & Failure $(n=15)$ & $p$-value* \\
\hline Sex & & & 0.692 \\
\hline Female & $45(41.3)$ & $7(46.7)$ & \\
\hline Male & $64(58.7)$ & $8(53.3)$ & \\
\hline Age (years) & $57.57 \pm 11.91$ & $56.13 \pm 10.16$ & 0.657 \\
\hline Tomita & $6.98 \pm 2.35$ & $6.73 \pm 1.58$ & 0.599 \\
\hline Preoperative adjuvant treatment & $67(61.5)$ & $8(53.3)$ & 0.546 \\
\hline Preoperative spinal radiotherapy & $35(32.1)$ & $6(40.0)$ & 0.567 \\
\hline Number of metastasis vertebrae & $3.56 \pm 3.88$ & $4.60 \pm 7.28$ & 0.595 \\
\hline Number of fixed vertebrae & $3.39 \pm 1.27$ & $3.33 \pm 1.23$ & 0.873 \\
\hline Use of bone graft & $54(49.5)$ & $8(53.3)$ & 0.783 \\
\hline Postoperative adjuvant treatment & $91(83.5)$ & $14(93.3)$ & 0.464 \\
\hline Postoperative spinal radiotherapy & $66(60.6)$ & $13(86.7)$ & 0.049 \\
\hline Tumor & & & 0.799 \\
\hline Kidney & $9(8.3)$ & $0(0.0)$ & \\
\hline Liver & $20(18.3)$ & $2(13.3)$ & \\
\hline Lung & $27(24.8)$ & $5(33.3)$ & \\
\hline Others & $53(48.6)$ & $8(53.3)$ & \\
\hline Extra bone meta & $68(62.4)$ & $10(66.7)$ & 0.748 \\
\hline ASIA grade & & & 0.164 \\
\hline$A$ & $1(0.9)$ & $0(0.0)$ & \\
\hline B & $2(1.8)$ & $0(0.0)$ & \\
\hline C & $12(11.0)$ & $5(33.3)$ & \\
\hline$D$ & $52(47.7)$ & $4(26.7)$ & \\
\hline$E$ & $42(38.5)$ & $6(40.0)$ & \\
\hline Approach & & & 0.391 \\
\hline Doral & $31(28.4)$ & $6(40.0)$ & \\
\hline Ventral & $54(49.5)$ & $8(53.3)$ & \\
\hline Doral+ventral & $24(22.0)$ & $1(6.7)$ & \\
\hline Corpectomy verterae & & & 0.550 \\
\hline C & $42(38.5)$ & $4(26.7)$ & \\
\hline $\mathrm{T}$ & $47(43.1)$ & $7(46.7)$ & \\
\hline$L$ & $20(18.3)$ & $4(26.7)$ & \\
\hline Survival time (days) & $385 \pm 565.9$ & $941 \pm 1486.8$ & 0.173 \\
\hline Ambulatory & $84(77.1)$ & $9(60.0)$ & 0.201 \\
\hline Bone mineral deinsity & $-0.88 \pm 1.26$ & $-0.56 \pm 0.99$ & 0.367 \\
\hline Use of steroid (yes) & $76(69.7)$ & $10(66.7)$ & 0.774 \\
\hline Fixation in osteolytic vertebrae (yes) & $52(47.7)$ & $9(64.3)$ & 0.243 \\
\hline
\end{tabular}

Values are presented as mean \pm standard deviation or number (\%). ${ }^{*} p<0.05$. ASIA : American Spinal Injury Association, $C$ : cervical spine, $T$ : thoracic spine, L: lumbar spine 
Instrument Failure of Metastatic Spine I Park SB, et al.

Table 3. Analysis of risk factors using logistic regression

\begin{tabular}{|c|c|c|c|c|}
\hline \multirow[t]{2}{*}{ Risk factor } & \multicolumn{2}{|c|}{ Univariable analysis } & \multicolumn{2}{|c|}{$\begin{array}{c}\text { Multivariable analysis variables with } \\
p<0.20 \text { in univariable analyses }\end{array}$} \\
\hline & OR $(95 \% \mathrm{Cl})$ & $p$-value & OR $(95 \% \mathrm{Cl})$ & $p$-value \\
\hline \multicolumn{5}{|l|}{ Sex } \\
\hline Female & Reference & & & \\
\hline Male & $0.804(0.272,2.375)$ & 0.692 & & \\
\hline Age & $0.990(0.946,1.036)$ & 0.654 & & \\
\hline Tomita & $0.953(0.750,1.209)$ & 0.689 & & \\
\hline Preoperative adjuvant treatment & $0.716(0.242,2.121)$ & 0.547 & & \\
\hline Preoperative spinal radiotherapy & $1.410(0.465,4.271)$ & 0.544 & & \\
\hline Number of metastasis vertebrae & $1.045(0.944,1.157)$ & 0.398 & & \\
\hline Number of fixed vertebrae & $0.965(0.622,1.497)$ & 0.872 & & \\
\hline Use of bone graft & $1.164(0.395,3.433)$ & 0.783 & & \\
\hline Postoperative adjuvant treatment & $2.768(0.342,22.392)$ & 0.340 & & \\
\hline Postoperative spinal radiotherapy & $3.533(1.004,18.639)$ & 0.049 & $3.535(1.001,18.701)$ & 0.050 \\
\hline Tumor & & 0.754 & & \\
\hline Kidney & $0.331(0.002,3.081)$ & 0.483 & & \\
\hline Liver & $0.768(0.136,3.086)$ & 0.734 & & \\
\hline Lung & $1.259(0.371,3.991)$ & 0.703 & & \\
\hline Others & Reference & & & \\
\hline Extra bone meta & $1.206(0.385,3.775)$ & 0.748 & & \\
\hline ASIA grade & & 0.242 & & \\
\hline A & Reference & & & \\
\hline B & $0.599(0.000,142.774)$ & 0.864 & & \\
\hline C & $1.319(0.060,205.308)$ & 0.907 & & \\
\hline $\mathrm{D}$ & $0.257(0.012,39.757)$ & 0.565 & & \\
\hline$E$ & $0.458(0.022,69.895)$ & 0.740 & & \\
\hline Approach & & 0.386 & & \\
\hline Doral & Reference & & & \\
\hline Ventral & $0.765(0.243,2.410)$ & 0.648 & & \\
\hline Doral+Ventral & $0.215(0.024,1.910)$ & 0.168 & & \\
\hline Corpectomy verterae & & 0.610 & & \\
\hline C & Reference & & & \\
\hline T & $1.564(0.427,5.721)$ & 0.499 & & \\
\hline $\mathrm{L}$ & $2.100(0.476,9.268)$ & 0.327 & & \\
\hline Ambulatory & $0.446(0.145,1.376)$ & 0.160 & $0.437(0.145,1.380)$ & 0.153 \\
\hline Bone mineral deinsity & $1.216(0.773,2.129)$ & 0.438 & & \\
\hline Use of steroid (yes) & $0.836(0.284,2.714)$ & 0.754 & & \\
\hline Fixation in osteolytic vertebrae (yes) & $1.891(0.635,6.165)$ & 0.266 & & \\
\hline
\end{tabular}

OR : odds ratio, Cl : confidence interval, ASIA : American Spinal Injury Association, C: cervical spine, T: thoracic spine, L : lumbar spine 
1 year, fixation augmentation such as long-level fixation or polymethylmethacrylate may be preferable over bone fusion.

\section{Limitations of the study}

This study has several limitations. The number of patients who experienced instrumentation failure was much smaller than the number of patients who did not, and this may complicate the interpretation of the statistical analysis. Therefore, we analyzed the data using logistic regression with Firth's specialized likelihood to reduce the risk of bias in the statistical analysis $^{7)}$. The small number of patients reflects the actual situation in the clinical treatment of patients with spinal metastases. In other words, our results reflect the fact that implant failure after surgery for spinal metastases occurs rarely and that bone grafting is not essential for preventing instrumentation failure in this particular group of patients. Another limitation is the long observational period, during which advances in surgical techniques may have affected the outcomes. Future studies should include more patients to allow for the identification of factors significantly associated with instrumentation failure. Another limitation is the retrospective study design, which means that the treatment strategies for patients with spinal metastasis were not consistent for all patients; in particular, the indications for bone grafting were not always strictly observed, and the use of bone grafting was performed at each surgeon's discretion. Hence, this individual discretion may have introduced a bias into the analysis of the value of bone grafting. In other limitation of the present study, although the radiotherapy was the significant factor related with instrument failure through statistical analysis, it seems not to be enough that the radiotherapy could be factor related with the early instrument failure within three months after surgery. The patients with spine metastasis may be advanced stage of cancer status. The patients' bone quality could be weak due to multiple factors including poor intake, decreased activity, micro-bone metastasis, and increased bone turnover. In the future study, we should consider variable causes related with the instrument failure in spine metastasis using big data

\section{CONCLUSION}

The use of postoperative radiotherapy may increase the likelihood of instrumentation failure after partial corpectomy in patients with a metastatic spine. Bone grafting may not as critical as expected for preventing instrumentation failure in patients with a life expectancy of less than 1 year.

\section{CONFLICTS OF INTEREST}

No potential conflict of interest relevant to this article was reported.

\section{INFORMED CONSENT}

Informed consent was obtained from all individual participants included in this study.

\section{- Acknowledgements}

This research was supported by Basic Science Research Program through the National Research Foundation of Korea (NRF) funded by the Ministry of Science, ICT and future Planning (2014R1A2A1A11049662).

\section{References}

1. Bilsky MH, Laufer I, Burch S: Shifting paradigms in the treatment of metastatic spine disease. Spine (Phila Pa 1976) 34(22 Suppl) : S101S107, 2009

2. Binning MJ, Gottfried $O N$, Klimo P Jr. Schmidt MH : Minimally invasive treatments for metastatic tumors of the spine. Neurosurg Clin N Am 15 : 459-465, 2004

3. Bouchard JA, Koka A, Bensusan JS Stevenson S, Emery SE : Effects of irradiation on posterior spinal fusions. A rabbit model. Spine (Phila Pa 1976) $19: 1836-1841,1994$

4. Coleman RE, Rubens RD : The clinical course of bone metastases from breast cancer. Br J cancer 55 : 61-66,1987

5. Emery SE, Brazinski MS, Koka A, Bensusan JS, Stevenson S : The biological and biomechanical effects of irradiation on anterior spinal bone grafts in a canine model. J Bone Joint Surg Am 76 : 540-548,1994

6. Emery SE, Hughes SS, Junglas WA Herrington SJ, Pathria MN : The fate of anterior vertebral bone grafts in patients irradiated for neoplasm. Clin Orthop Relat Res (300) : 207-212, 1994

7. Firth $D$ : Bias reduction of maximum likelihood estimates. Biometrika $80: 27-38,1993$

8. Gerszten PC, Welch WC : Current surgical management of metastatic spinal disease. Oncology (Williston Park) 14 : 1013-1024; discussion 1024, 1029-1030, 2000 
9. Grant R, Papadopoulos SM, Greenberg HS : Metastatic epidural spinal cord compression. Neurol Clin 9 : 825-841, 1991

10. Harel R, Chao S, Krishnaney A, Emch T, Benzel EC, Angelov L. Spine instrumentation failure after spine tumor resection and radiation: comparing conventional radiotherapy with stereotactic radiosurgery outcomes.

World Neurosurg 74 : 517-522, 2010

11. Hatrick NC, Lucas JD, Timothy $A R$, Smith MA : The surgical treatment of metastatic disease of the spine. Radiother Oncol 56 : 335-339, 2000

12. Jacobs WB, Perrin RG : Evaluation and treatment of spinal metastases: an overview. Neurosurg Focus 11 : e10, 2001

13. Jung KW, Park S, Kong HJ, Won YJ, Lee JY, Park EC, et al. : Cancer statistics in Korea: incidence, mortality, survival, and prevalence in 2008. Cancer Res Treat 43 : 1-11, 2011

14. Kim CH, Chung CK, Sohn S, Lee S, Park SB : Less invasive palliative surgery for spinal metastases. J Surg Oncol $108:$ 499-503, 2013

15. Kim JM, Losina E, Bono CM, Schoenfeld AJ, Collins JE, Katz JN, et al. : Clinical outcome of metastatic spinal cord compression treated with surgical excision \pm radiation versus radiation therapy alone: a systematic review of literature. Spine (Phila Pa 1976) 37 : 78-84, 2012

16. Klimo P Jr, Thompson CJ, Kestle JR, Schmidt MH : A meta-analysis of surgery versus conventional radiotherapy for the treatment of metastatic spinal epidural disease. Neuro Oncol 7 : 64-76, 2005

17. Kwok Y, Tibbs PA, Patchell RA : Clinical approach to metastatic epidural spinal cord compression. Hematol Oncol Clin North Am 20 : 12971305,2006
18. Mantravadi RV, Skolnik EM, Applebaum EL : Complicationsof postoperative and preoperative radiation therapy in head and neck cancers. A comparative study. Arch Otolaryngol 107 : 690-693, 1981

19. Maranzano E, Trippa F, Chirico L, Basagni ML, Rossi R : Management of metastatic spinal cord compression. Tumori 89 : 469-475, 2003

20. Miller DJ, Lang FF, Walsh GL, Abi-Said D, Wildrick DM, Gokaslan ZL : Coaxial double-lumen methylmethacrylate reconstruction in the anterior cervical and upper thoracic spine after tumor resection. J Neurosurg 92(2 Suppl) : 181-190, 2000

21. Riseborough EJ : Irradiation induced kyphosis. Clin Orthop Relat Res (128) : 101-106, 1977

22. Roodman GD : Mechanisms of bone metastasis. N Engl J Med 350 : 1655-1664, 2004

23. Sohn S, Kim J, Chung CK, Lee NR, Park E, Chang UK, et al. : A nationwide epidemiological study of newly diagnosed spine metastasis in the adult Korean population. Spine J 16 : 937-945, 2016

24. Sugimoto M, Takahashi S, Toguchida J, Kotoura Y, Shibamoto Y, Yamamuro $\mathrm{T}$ : Changes in bone after high-dose irradiation. Biomechanics and histomorphology. J Bone Joint Surg Br 73 : 492-497, 1991

25. Tomita K, Kawahara N, Kobayashi T, Yoshida A, Murakami H, Akamaru $\mathrm{T}$ : Surgical strategy for spinal metastases. Spine (Phila Pa 1976) 26 : 298-306, 2001

26. Vrionis FD, Small J : Surgical management of metastatic spinal neoplasms. Neurosurg Focus 15 : E12, 2003 